\title{
FACTORS LIMITING THE DEVELOPMENT OF NEW CONTRACEPTIVES
}

\author{
J. P. BENNETT \\ Syntex Corporation, Stanford Industrial Park, Palo Alto, California, U.S.A.
}

\begin{abstract}
Summary. Future production of entirely new contraceptives will proceed more slowly than in the past due to the lack of basic knowledge in reproductive physiology, the increasingly restrictive government drug-regulatory controls for new contraceptives and the lack of sufficient and suitable research support by industry and government. Some of these restrictions towards discovery of new contraceptives may be overcome by the WHO Expanded Program if they can avoid the mistakes of similar government research support groups. This programme holds out some hope for quickly bringing suitable contraceptive technology to the underdeveloped nations of the world where the major population control problem lies.
\end{abstract}

Cooper (1969), in a paper presented to the Royal Society of Medicine, stated that: 'All progress tends to be inhibited by spontaneously arising negative forces which ... eventually offset or kill the progress with which they are associated'. The recent publications of Djerassi $(1969,1970,1971)$, Bloom (1970), Harkavy \& Maier (1970) and Tishler (1971) among others, have shown that the premise of Cooper (1969) may well be correct when referring to the development of new drugs, particularly of new contraceptives.

Using the deHaen New Product Survey and the Non-Proprietary Name Index as sources to cull the dates and number of U.S. new product introductions, an index has been compiled by Bloom (1970) of the rate at which new drugs are being discovered and developed through the world (Text-fig. 1). In constructing these figures it is assumed that the sponsors of any significant new drug are strongly motivated to make it available commercially in the United States as early as possible and that the variance between drugs in the time period from discovery to U.S. market introduction is minimized by restricting analysis to comparisons involving periods of time of not less than 5 years.

The peak period for introduction of new drugs was during the late 1950s. A rapid decline in new drug introductions occurred with the issuing in 1962 of the Kefauver-Harris Amendment to the Food and Drug Act, under which the Food and Drug Administration (FDA) derives its authority. This Act was passed in the wake of the thalidomide tragedy. During the last decade, the number of new drugs introduced has dropped by approximately $70 \%$ from the high levels of 1960, with $50 \%$ of this decrease occurring during the years 1961-65. It should be emphasized that we are discussing the significant products of 


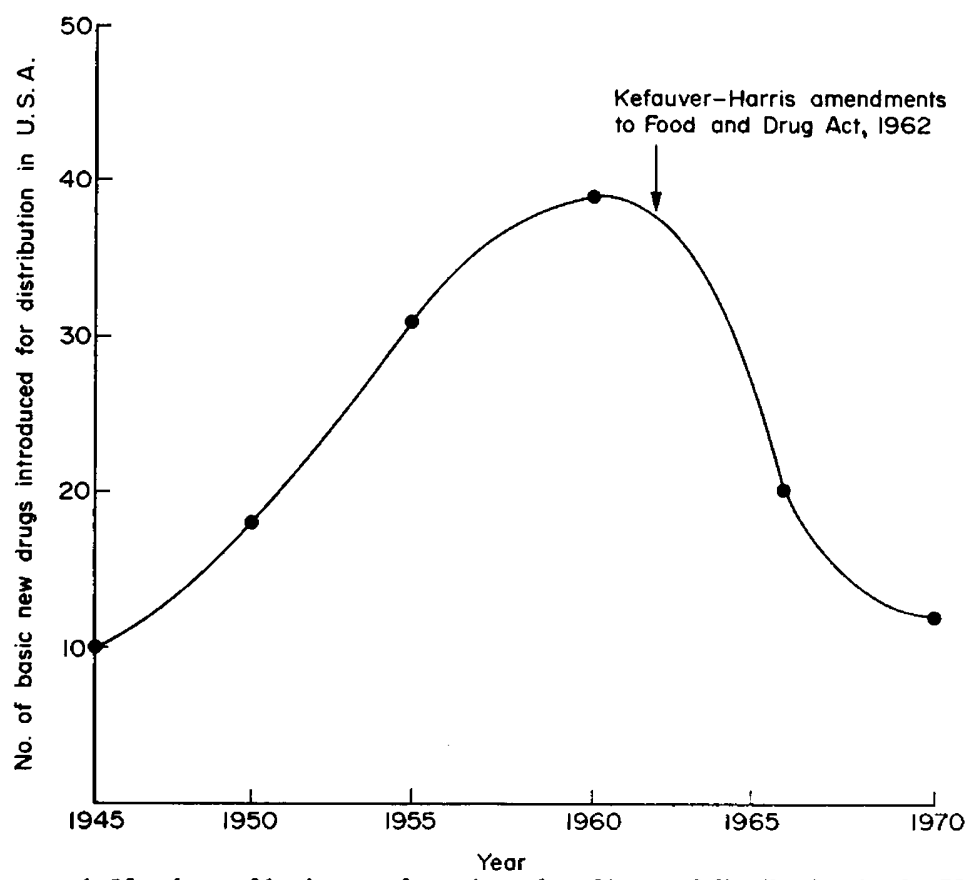

TEXT-FIG. 1. Numbers of basic new drugs introduced/year of distribution in the United States.

discovery research, the basic new agents or new single entity drugs, not duplicate products and minor combinations upon which industry had substantially reduced development well before the introduction of the 1962 drug law amendments.

During this period of decreased new drug introductions, the first oral contraceptive was marketed in 1962, followed shortly thereafter by several others. Since then, there has been substantial research in chemical contraception, but as yet no original methods of chemical contraception have been introduced for wide-scale use.

The deHaen data compiled through years 1968-70 suggest that new single entity drugs are being approved and marketed at a greater rate in countries other than the United States (Table 1). Thirty-one of a list of fifty new pharma-

Table 1. New single chemicals introduced. (From Bloom, 1970.)

\begin{tabular}{l|c|c|c}
\hline Country & 1968 & 1969 & $\begin{array}{c}1970 \\
\text { (first 6 months) }\end{array}$ \\
\hline U.S.A. & 11 & 9 & 7 \\
U.K. & 18 & 21 & 19 \\
Germany & 30 & 33 & 17 \\
France & 27 & 16 & 20 \\
Italy & 14 & 8 & 18 \\
Japan & - & $22^{*}$ & 14 \\
\hline
\end{tabular}

* Introduction of Japan's drug regulatory agency. 
ceutical drugs in pharmaceutical research and development in the United States, identified by the 1972 deHaen 'watchlist' as promising new drugs, have already been marketed in foreign countries. This observation suggests marked differences in the philosophy of the drug regulatory agencies between different countries. Thus, a new contraceptive drug may be released for distribution in one country and not in another according to whether the drug succeeds in passing the nationally prescribed drug regulations.

These differences in required drug regulations between countries impose the need for an international marketing company to maintain a large administrative department to service these requirements, further increasing the cost of drug development.

Although the United States maintains the biggest effort in total time and investment in the development of new drugs, the number of new drugs reaching the public is smaller than in other countries. In the case of the oral contraceptives the picture is particularly dismal. There are several reasons to explain this prognosis for new contraceptive development, especially in the United States. One of these is the influence of the drug regulatory agencies on contraceptive development.

\section{THE INFLUENCE OF THE DRUG REGULATORY AGENCIES}

All new drugs, before human clinical testing, must satisfy the established criteria of national drug regulatory agencies for safety by toxicological testing in animals. The public should obviously be protected from all reasonably foreseeable drug hazards, but this task is difficult since drug safety regulations must attempt to protect the public without hindering research for new drugs. Regulations in the United States pertaining to the toxicology studies for the introduction of drugs used in the treatment of human diseases that are not chronic have become increasingly demanding (Table 2 ). The regulations are more extensive

Table 2. Animal toxicology required by the FDA for oral or parenteral use of a new drug in the clinic

\begin{tabular}{l|l|l}
\hline $\begin{array}{c}\text { Dutration of human } \\
\text { administration }\end{array}$ & Clinical phase tested* & $\begin{array}{c}\text { Subacute or chronic toxicity } \\
\text {-two species by route used } \\
\text { clinically }\end{array}$ \\
\hline Several days & I up to NDA $\dagger$ & 2 weeks \\
Up to 2 weeks & I & 2 weeks \\
& II & Up to 4 weeks \\
Up to 3 months & III, NDA & Up to 3 months \\
& I, II & 4 weeks \\
III & NDA & Uponths \\
& I, II & 3 months \\
& III & 6 months or longer \\
& NDA & 12 months non-rodent \\
& IV & 18 months rodent \\
\hline
\end{tabular}

* Definitions described in $\$ 130$ of New Drug Regulations, FDA.

$\dagger$ NDA = New Drug Application.

$\$$ Acute toxicity determined in three or four species. 
Table 3. Some regulatory agency requirements for animal toxicity studies for nonsteroidal and steroidal contraceptives

\begin{tabular}{|c|c|c|}
\hline Clinical use & $F D A$ & U.K. committee on safety of medicine \\
\hline $\begin{array}{l}\text { Small nos. of patients } \\
\text { Few days } \\
\text { No reproductive risk }\end{array}$ & 90 -days rats, dogs, monkeys & 90 -day rat, non-rodent \\
\hline $\begin{array}{l}\text { With reproductive risk } \\
\text { (equiv. phase 1) }\end{array}$ & $\begin{array}{l}\text { Plus teratology in rodent } \\
\text { and fertility and reproductive } \\
\text { performance female rodent }\end{array}$ & Plus teratology in rat and rabbit \\
\hline $\begin{array}{l}\text { Controlled no. up to } \\
\text { three cycles } \\
\text { (equiv. phase II) }\end{array}$ & 1-year rat, dog, monkey & 6-months rat, non-rodent \\
\hline $\begin{array}{l}\text { Unlimited no. patients } \\
\text { (equiv. phase III) }\end{array}$ & $\begin{array}{l}\text { 2-year rat (carcinogenesis) } \\
7 \text {-year dog (in progress } 2 \text { years) } \\
\text { 10-year monkey (in progress } 2 \text { years) } \\
\text { Peri- and post-natal fertility rodent } \\
\text { Fertility and reproductive } \\
\quad \text { performance male rodent }\end{array}$ & $\begin{array}{l}\text { 2-year rat } \\
\text { 18-months mouse (carcino- } \\
\text { genesis) }\end{array}$ \\
\hline
\end{tabular}

for the chemical contraceptives (Table 3 ) where a drug may be given to healthy women for prolonged periods. The extremely high cost in manpower, facilities, materials, clinic patients and the duration required to develop this enormous amount of data (Text-fig. 2) has severely impaired drug development in this field.

The patent life-span of a new drug in many countries is 17 years or less. The

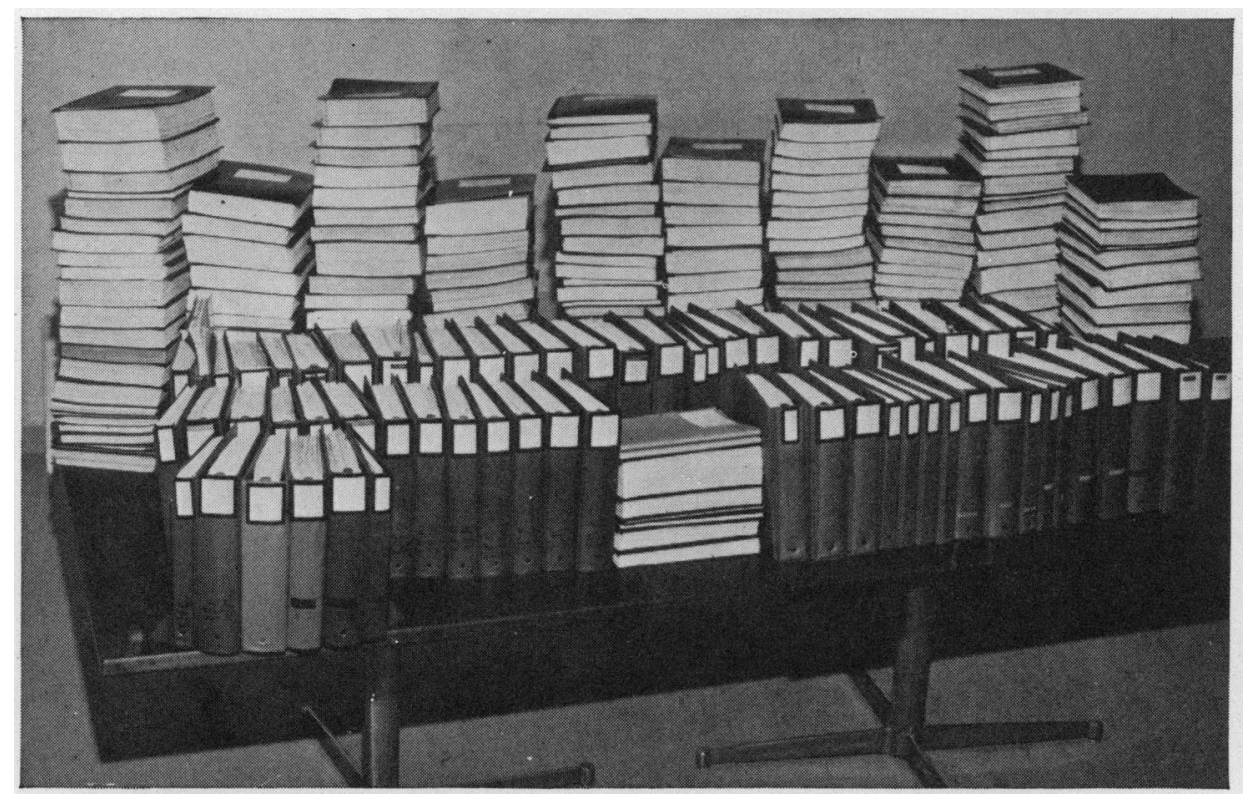

TEXT-Fig. 2. A typical submission to the FDA of a new drug application for an oral hormonal contraceptive. The volumes illustrated are one complete set and must be submitted in triplicate. 
duration required to produce the necessary data for the regulatory agencies (6 to 8 years) increases the overall development time of a new chemical contraceptive to about 10 years, eating deeply into the patent life of the drug. Hopes of a commercial return on the high research investments are thus extremely poor for chemical contraceptives, compared to returns from other drugs used against disease. There are indications that even disease-controlling drugs are taking longer and costing more to develop as the influence of the regulatory agencies spreads. For example, in June 1971, Lederle introduced a new antibiotic which took 10 years of research and development, including 4 years of laboratory and animal testing and 6 years in clinical testing at a cost of $\$ 7$ million, with a further $\$ 3$ million required in manufacturing plant.

The FDA does not stipulate the animal species required in the testing of most new drugs, but the rat, beagle dog and monkey were arbitrarily selected as animals for compulsory testing of oral contraceptives. Obviously, the most acceptable species apart from the human is the one where the observed druginduced effects in an animal species are comparable to those observed in the human. There are sound scientific reasons indicating that the beagle dog is unsuitable as a test animal, because of its bi-annual heat cycle and its unusual metabolism and peculiar sensitivity to steroidal compounds (Hill, Averkin, Brown, Gagne \& Segre, 1970). Further, it is doubtful if wild, trapped monkeys of unknown genetic and health heritage satisfy such a criterion. The dose levels requested by the FDA for toxicology studies with contraceptive compounds are direct multiples of the human dose on a body weight basis without regard to the biological potency of the drug in the test species (Table 4), making irrelevant

Table 4. Relative progestational potencies of chlormadinone and norethindrone in human and canine species

\begin{tabular}{c|c|c}
\hline Species & Chlormadinone & Norethindrone \\
\hline Human & 5 & 1 \\
Canine & 225 & 1 \\
\hline
\end{tabular}

the comparisons of results in animals to the human. Dose levels on a body weight basis for long-term toxicity studies were designated as ten and twenty-five times the human dose in dogs and ten and fifty times the human dose in monkeys.

The elaborate regulatory requirements governing the development of oral contraceptives are among the chief reasons why so many large pharmaceutical companies have either completely ceased all research toward new contraceptives or have markedly reduced their research expenditures in this area. A unique oral chemical contraceptive with a new mechanism of action now costs about $\$ 10$ million to develop over a time space of about 10 to 14 years (Table 5). Controversial results from the toxicological testing of contraceptive compounds in animals, sometimes of doubtful relevance to the human, can result in complete loss of research investment by the arrest of all research and immediate suspension 
Table 5. Chronology of development of chlormadinone acetate as a minipill contraceptive

\begin{tabular}{l|l}
\hline \multicolumn{1}{c|}{ Stage of development } & rear \\
\hline Chemical synthesis & 1957 \\
Discovered & 1958 \\
Biological testing & 1958 \\
Toxicity testing & $1959-79$ \\
Clinical testing-Mexico & $1964-70$ \\
Uarketing of minipill & $1965-70$ \\
New drug application-Food and Drug Admin. U.S.A. & 1969 \\
Withdrawn from market & 1969 \\
Resubmitted to U.K. Committee on Safety of.Drugs & 1970 \\
& 1971 \\
\hline
\end{tabular}

of testing or marketing by the drug companies. This happened to three marketed oral contraceptives in 1970.

Decisions by the regulatory agencies before marketing are essentially without appeal. This fact has important repercussions in the international use of contraceptive development in the United States since the export of such contraceptives for clinical use in a foreign country is subject to the approval by the FDA of the foreign clinical protocol and is also subject to withdrawal during the investigative phase. The removal of the chlormadinone acetate minipill from marketing abroad is an example. This compound has been used successfully in over 2 million human cycles with a low incidence of side effects. In addition, chlormadinone acetate has been administered for over 3 years to monkeys without significant toxic effects. In dogs, however, chlormadinone acetate administration resulted in the formation of mammary gland nodules, a type of tumour which is very common in the dog. The relevance of these findings to the possible human experience is highly questionable, particularly under the experimental conditions imposed by the FDA. Nevertheless, solely on the basis of these results in dogs, regulatory agencies have prevented a most promising contraceptive from reaching the public.

The FDA and other international drug regulatory agencies are introducing toxicological requirements for such new contraceptive innovations as the copper IUD and the prostaglandins used as once-per-month menses-inducers or abortifacients. The FDA in June of 1971 prevented the copper IUD from being marketed until satisfactory toxicological data was accumulated, since the addition of copper to the IUD was construed as a form of drug-induced chemical contraception. Regulations are also in preparation for control over the testing of devices not containing chemicals, including the plastic IUDs now used widely in the human.

The final regulations controlling the clinical testing of prostaglandins as contraceptives are not yet complete, but rough guide-lines have been established by the FDA (Table 6). They form the basis for requirements as extensive, expensive and time-consuming as those applied to the oral contraceptives.

It is no coincidence that the new contraceptive technologies, such as the copper IUD, the prostaglandins and chemical sterilants like quinacrine, have been 
Table 6. Suggested toxicology requirements (FDA) for development of intravaginal prostaglandin contraceptive/abortifacient

\begin{tabular}{l|l}
\hline Phase I & $\begin{array}{l}\text { Intravaginal tolerance test } 2 \text { weeks, three species, ten animals/dose including monkey. } 1,3 \\
\text { and } 10 \times \text { human dose }\end{array}$ \\
Phase II & $\begin{array}{l}\text { A. } 3 \text { months in twenty rabbits, twenty hamsters, ten monkeys } 1,3 \text { and } 10 \times \text { human dose } \\
\text { B. Teratology studies in rats and rabbits with subcontraceptive doses } \\
\text { Special tests to show absence of adverse effects on future fertility from repeated cyclic } \\
\text { disruption of initiated pregnancies }\end{array}$ \\
Phase III & $\begin{array}{l}1 \text { year interim to autopsy of rabbit, hamster and monkey } 1,3 \text { and } 10 \times \text { human dose } \\
\text { Complete 2-year chronic toxicity in rabbit, hamster and monkey. Continue additional } \\
\text { monkeys for several years }\end{array}$ \\
\hline
\end{tabular}

developed most rapidly in countries outside the jurisdiction of the drug regulatory agencies.

\section{THE INFLUENCE OF EXTERNAL FORGES}

The controversial nature of research on contraception has unfortunately always led to an arousing of social and lay pressures which influence development of new contraceptives. Unfortunately too, the reports of the lay press on oral contraceptive practice have often increased the fears of the public by misrepresentation of the scientific facts. These reports create an atmosphere which influences the judgment of those supporting contraceptive research and also of the FDA which is answerable to Congress for its actions and whose decisions are subject to political and journalistic pressures.

Thus, after the Nelson Committee Hearings in the United States during early 1970 , the adverse publicity resulted in about $18 \%$ of the $8 \frac{1}{2}$ million Americans ceasing to use the oral contraceptives, with a consequent increase in the number of unwanted pregnancies. The events at this time led to a severe re-appraisal of contraceptive research in many pharmaceutical companies, and the first cutbacks in research expenditures in this area were initiated.

Physicians must realize that every drug should be judged by the ratio of benefit to risk and that a completely safe and effective drug does not exist. The safety risk of a chemical contraceptive weighed against the desired degree of protection from pregnancy is a matter of individual value judgment of the patient, upon the advice of the physician.

\section{THE INFLUENGE OF RISING RESEARCH COSTS}

The development of a chemical contraceptive requires highly sophisticated multidisciplinary research which is exceedingly costly. Djerassi (1970) has recently observed that, during the years 1965-69, the combined expenditure in contraceptive research of five major pharmaceutical companies (Lilly, Ortho, Syntex, Searle, Upjohn) was about $\$ 68$ million. He estimated that the total of such expenditures for all pharmaceutical companies during this time was about $\$ 100$ million. Similar sums of money for contraception research will certainly not be invested by industry in the immediate future for reasons outlined in this paper. 
While the pharmaceutical research companies were the major developers and suppliers of new contraceptive agents in the past, some of the fundamental work leading to such development originated in the research laboratories of universities, government and private institutions. Funds for such research, in the past, have been regrettably small considering the importance of the population control problem (Table 7) and the lack of basic knowledge in reproductive

Table 7. Annual support for research and training in reproductive biology,* in millions of dollars, 1966-70. (From Harkavy \& Maier, 1971.)

\begin{tabular}{|c|c|c|c|c|c|}
\hline Grants & 1966 & 1967 & 1968 & 1969 & 1970 (est.) \\
\hline National Institute of Health & $5 \cdot 0$ & $7 \cdot 1$ & $7 \cdot 1$ & $9 \cdot 9$ & $13 \cdot 5$ \\
\hline National Science Foundation & & & 0.3 & 0.4 & 0.4 \\
\hline Ford Foundation (Population Office) & $4 \cdot 4$ & $5 \cdot 7$ & $5 \cdot 6$ & $7 \cdot 0$ & $7 \cdot 0$ \\
\hline Ford Foundation (Regional Offices) & $0 \cdot 8$ & $0 \cdot 6$ & $0 \cdot 6$ & $0 \cdot 65$ & 0.65 \\
\hline Population Council $†$ & 0.3 & 0.4 & 1.0 & $1 \cdot 0$ & 1.0 \\
\hline Rockefeller Foundation & 0.02 & 0.02 & $0 \cdot 1$ & 0.7 & 0.7 \\
\hline Agency for International Development & - & - & - & $5 \cdot 9$ & $10 \cdot 0 \pm$ \\
\hline SIDA & - & - & - & 0.05 & $0 \cdot 1$ \\
\hline University Budgets $\S$ & $0 \cdot 8$ & $1 \cdot 0$ & $1 \cdot 1$ & $1 \cdot 4$ & $1 \cdot \overline{4}$ \\
\hline Total & $11 \cdot 3$ & $14 \cdot 8$ & $15 \cdot 8$ & $26 \cdot 9$ & $34 \cdot 75$ \\
\hline
\end{tabular}

* Exclusive of construction funds. Grants and in-house research and development expenditures by pharmaceutical firms are also excluded from this table.

$\dagger$ Net of Ford Foundation, Rockefeller Foundation and AID contributions.

\# Based on preliminary estimates by AID staff; no formal commitment.

$\S$ Estimated at $15 \%$ of non-government support.

physiology and contraceptive mechanisms. Each year the Ford and Rockefeller Foundations and the Population Council finance, on average, only one-third of research proposals received. Harkavy \& Maier (1970) placed such funding in perspective by comparing the $\$ 35$ million spent in 1970 on population research with the $\$ 275$ million a year spent on cancer research, a sum markedly increased in 1972.

The introduction of the Contraceptive Development Branch by the United States National Institute of Child Health and Human Development (NIHCD) in 1969 was a big step forward in directing research toward new approaches to contraception. Yet again the funds allocated remain insufficient to support all acceptable research contracts and grants (Table 8). Since NIHCD allocates funds annually, it must always reserve continuing support funds for projects previously approved, leaving little available for new project allocations.

In 1970, the NIHCD initiated a programme of contract research with the hope of establishing much needed collaboration with industry in developing new contraceptives. Such collaboration has unfortunately been slow in realization. In the fiscal year 1971, only twelve research contracts were allocated to industrial establishments at an annual cost of $\$ 1,191,151$. In the fiscal year 1972 , the eleven industrial research contracts financed cost $\$ 1,588,677$, but the non-industrial contracts funded cost $\$ 10,067,565$. One of the chief reasons for the slowness of industry to involve themselves with this programme is the restrictive patent laws of the NIH, whereby the Assistant Secretary (Health and 


\begin{tabular}{|c|c|c|c|}
\hline 胥 & 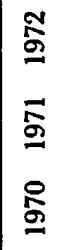 & 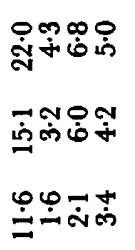 & $\begin{array}{l}\overrightarrow{\dot{\phi}} \\
\text { in } \\
\dot{\sim} \\
\dot{\phi} \\
\dot{\phi}\end{array}$ \\
\hline 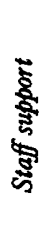 & 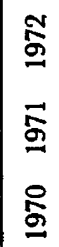 & 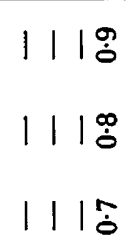 & $\begin{array}{l}\stackrel{\phi}{0} \\
\dot{\phi} \\
\dot{0} \\
\dot{\delta}\end{array}$ \\
\hline 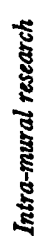 & 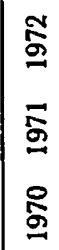 & 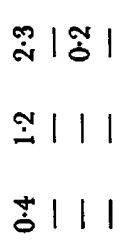 & $\begin{array}{l}\stackrel{0}{\pi} \\
\stackrel{n}{*}\end{array}$ \\
\hline 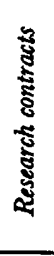 & 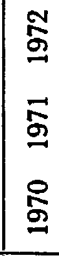 & 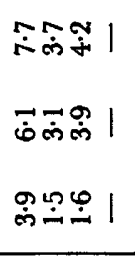 & 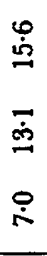 \\
\hline 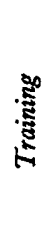 & 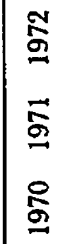 & 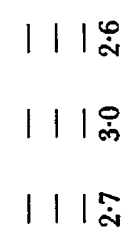 & $\begin{array}{l}\dot{\omega} \\
\dot{\infty} \\
\dot{\omega}\end{array}$ \\
\hline 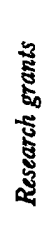 & 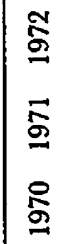 & 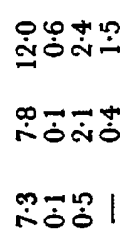 & $\begin{array}{l}\dot{0} \\
\dot{0} \\
\dot{0} \\
\stackrel{0}{\dot{0}}\end{array}$ \\
\hline & E & 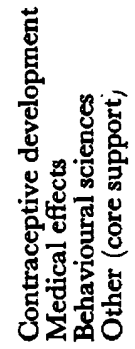 & 좀 \\
\hline
\end{tabular}


Scientific Affairs) 'shall have the sole and exclusive power to determine whether or not and where a patent application shall be filed, and to determine the disposition of all rights in such invention, including title to and rights under any patent application or patent which may issue thereon. The determination of the Assistant Secretary (Health and Scientific Affairs) on all these matters shall be accepted as final and the provisions of the clause of this contract entitled disputes shall not apply ...'

Other reasons producing a lack of enthusiasm to collaborate in this scheme are the inflexibility in organizational and policy matters affecting NIH research funds, coupled with an obligation to interact with a whole bureaucratic system of project controls.

At present, it would appear that the current government research funds for reproductive biology and contraception are mostly utilized by the universities and private contract organizations (e.g. Battelle, Stanford Research Institute) as a useful means of supplementing the necessary support of research staff and laboratories.

The World Health Organization has initiated an Expanded Program in support of training and of research towards new contraceptives. This organization is keen to enlist the support of the pharmaceutical industry and will probably be successful by working under more enlightened patent rules than NIHCD. The rights of any new contraceptive developed from funds of the Expanded Program would be delegated to WHO in the public sector and to industrial collaborators in the private sector. There is an intention to avoid an overbureaucratic control of projects. An important and unique feature is that experienced industrial scientists will play a significant rôle as advisors to the WHO Expanded Program.

Development costs for new contraceptives should generally be divided into two categories. Firstly, funds are required to expand fundamental knowledge in reproduction especially in the human and non-human primate. Secondly, support is needed for investigation of the existing specific leads that could be developed into new contraceptives. The combined costs for this work are estimated at about $\$ 500$ million over the next 5 years taking into consideration cost estimates allocated by Southam \& Harkavy (1967) and Segal (1970). This work should be divided between the universities and the industrial and government laboratories. Additional funds would be required for the further development of the new contraceptive technology through toxicological and clinical research once the leads have been provided to a new contraceptive process. This work should be done by the pharmaceutical firms. Assuming ten compounds per study at any one time, at a total cost of $\$ 5$ million each, an extra $\$ 50$ million would be required over 5 years.

The total estimated funds required to support a research enterprise is thus between $\$ 500$ and $\$ 600$ million over 5 years, which is close to the figure of $\$ 150$ to $\$ 200$ million/year suggested in the 1969 report of the Ford Foundation as being the necessary funds required to support an optimum research effort 'considering the extraordinary complexity of the scientific questions that need investigation, the relatively primitive state of scientific research in this field and the urgency of finding ways to slow down world population growth'. 
The pharmaceutical industry has previously borne the major cost, and the risks, of new contraceptive research and development. However, many in the industry are gradually withdrawing support for this area of research due to the high commercial risk. Therefore, if momentum is to continue and build up in the search for new contraceptives, it is necessary for the government both to expand available research funds in fundamental reproductive biology and to accept some of the risk in contraceptive development.

Funds allocated to university or to non-profit research institutions need not be refundable. Industry could proceed with a shared risk in development. Djerassi (1970) has suggested that, in the event of government-supported toxicology and clinical research leading to a new contraceptive, the company should be obliged to repay the accumulated financial support on an annual royalty basis, not to exceed $5 \%$ to avoid influencing sale prices. An alternative suggested by Harkavy \& Maier (1970) is the possibility of having a non-profit organization with national or international support to carry out these studies without charge for contracting pharmaceutical companies. Either system might well lead to a re-appraisal by many pharmaceutical firms of their reluctance further to support research toward new contraceptives.

\section{THE INFLUENGE OF LAGK OF KNOWLEDGE ON CONTRACEPTIVE DEVELOPMENT}

Because of the extensive government regulatory requirements, the insufficient funding of contraceptive research and the gradual withdrawal of support of the pharmaceutical industry, the new chemical contraceptives of the next decade will, apart from the copper IUD, probably be new formulations and drug delivery systems of existing contraceptive steroids. The aim will be to release the steroid drug at the target organ in the lowest possible dose sufficient to be contraceptive.

One would suppose that such an aim might be quickly reached, but the factors interfering with progress have been listed by Diczfalusy (1971). This lack of knowledge of the steroid drugs even to the point of incompletely understanding their mechanism of contraceptive action in man is of great concern. Progress will be slow in this area of development and we cannot expect rapid discovery and wide public distribution of new steroidal contraceptives in the near future. Diczfalusy (1971) states, 'in the absence of sufficient comparative data, it is not yet possible to formulate common denominators which are valid in general terms for the endocrine regulation of the reproductive processes. This fact, together with our incomplete knowledge of the forms in which contraceptive steroids act at the cellular or subcellular level and the paucity of information on their tissue distribution, plasma half-life, metabolism and mechanism of action, constitute the major obstacles to the development of better steroidal contraceptive agents'. The lack of knowledge is even greater in non-steroidal contraceptive development.

\section{REFERENCES}

BLoom, B. M. (1970) The rate of contemporary drug discovery. Presented at the Ann. Meet. of Pharmaceutical Manufacturers Association, Research and Development Section, October, Florida, U.S.A. 
Cooper, J. D. (1969) The sociology of innovation in medicine. Proc. R. Soc. Med. 62, 48.

Diczralusy, E. (1971) Contraceptive steroids and their mechanism. In Control of Human Fertility. Nobel Symposium 15. Eds. E. Diczfalusy and U. Borell. Almquist \& Wiksell, Stockholm.

DJerassi, C. (1969) Prognosis for the development of new chemical birth-control agents. Science, N.Y. 166, 468.

DJERASSI, G. (1970) Birth control after 1984. Science, N.Y. 169, 941.

DJerassi, C. (1971) Reversible fertility control. Presented at the Int. Union of Pure and Applied Chemistry, July, Boston, U.S.A.

HaRkavy, O. \& MaIER, J. (1970) Research in reproductive biology and contraceptive technology; present status and needs for the future. Fam. Plann. Perspect. 2, 3.

HARKAVy, O. \& MaIER, J. (1971) Research in contraception and reproduction: a status report. Fam. Plann. Perspect. 3, 16.

Hill, R., Averkin, E., Brown, W., Gagne, W. E. \& Segre, E. (1970) Progestational potency of chlormadione acetate in the immature beagle bitch. Contraception, 2, 381.

SEGAL, S. (1970) Cited in Harkavy \& Maier (1970).

Southam, A. L. \& Harkavy, O. (1967) Resources for research and reproduction. In Implementing DHEW Policy on Family Planning and Population. Sept. 1967, U.S. Govt. Publication Office.

Tishler, M. (1971) What information does the medicinal chemist really need? Projections for the future. F. chem. Document. 11, 134. 